\title{
Adsorption of Diclofenac and Triclosan in Aqueous Solution by Purified Multi-Walled Carbon Nanotubes
}

\author{
Xiang Hu${ }^{1 *}$, Zhao Cheng ${ }^{1}$, Zhirong Sun ${ }^{2}$, Hong Zhu ${ }^{1}$ \\ ${ }^{1}$ College of Chemical Engineering, Beijing University of Chemical Technology, \\ Beijing 100029, China \\ ${ }^{2}$ College of Environmental and Energy Engineering, Beijing University of Technology, \\ Beijing 100124, China
}

Received: 16 April 2016

Accepted: 26 June 2016

\begin{abstract}
The ability of purified multi-walled carbon nanotubes (MWCNTs) to adsorb diclofenac and triclosan in aqueous solutions was examined by equilibrium, kinetic, and thermodynamic parameters. The results of SEM image, BET specific surface area, XRD, TGA, and FTIR spectra indicated that the characteristics of MWCNTs were improved after purification with nitric acid. Batch experiments illustrated that the removal efficiency of diclofenac and triclosan depended mostly on the MWCNTs dosage, temperature, ion concentration, $\mathrm{pH}$, and initial concentration. The maximum adsorption capacity for diclofenac and triclosan under optimum conditions was $19.9 \mathrm{mg} \mathrm{g}^{-1}$ and $19.7 \mathrm{mg} \mathrm{g}^{-1}$, respectively. The equilibrium data showed that adsorption behavior of diclofenac and triclosan could be described more reasonably by the pseudosecond-order model. Thermodynamic simulation showed that the adsorption was fitted with Langmuir and Freundlich adsorption isotherm, and the thermodynamic parameters revealed the process to be exothermic and spontaneous. In addition, the adsorption behavior of MWCNTs in the binary solution was successfully predicted using the ideal adsorbed solution theory. Finally, the adsorption mechanism was discussed.
\end{abstract}

Keywords: multi-walled carbon nanotubes, diclofenac, triclosan, adsorption kinetics, thermodynamic simulation

\section{Introduction}

As emerging contaminants, pharmaceutical and personal care products (PPCPs), which contain a variety of life-related substances such as prescription and nonprescription drugs and daily necessities, have been

*e-mail: huxiang@mail.buct.edu.cn developed in recent years [1]. However, according to the current research, most PPCPs are soluble in water, resulting in their accumulation and concentration increase in the environment, and environmental issues subsequently come into being [2]. Although the residual quantity of PPCPs is at a low level, the potential and longstanding harm to ecology and humans is incalculable. So PPCPs are attracting the attention of researchers [34]. Investigations of PPCPs have been carried out for 
a few decades already, but there is still a long way to go for human beings. The potential negative effects of PPCPs on humans could worsen if existing sewage treatment methods are not improved. In this paper, diclofenac and triclosan were selected as the target pollutants in order to study their adsorption behaviors on MWCNTs.

Diclofenac, a kind of white crystalline powder at room temperature, is a potent, non-steroidal, and antiinflammatory analgesic drug whose potency is superior to both indomethacin and aspirin. The concentration of diclofenac has now reached a higher level from $n g \mathrm{~L}^{-1}$ to $\mu \mathrm{g} \mathrm{L}^{-1}$ in the environment due to its continuous use [5]. At this concentration, diclofenac can adversely affect the ecosystem and threaten human comfort [6]. Triclosan, a kind of white crystalline powder at room temperature, is an effective broad-spectrum antimicrobial agent. But the widespread use and special nature of triclosan, namely difficult decomposition and non-volatility [7], have led to its accumulation in the environment, showing a concentration of 4-1,023 ng L-1 or even higher. Based on the literature, triclosan may affect the reproduction of aquatic organisms and produce a toxic effect on organs of animals [8].

In recent years, researchers have gradually given much attention to the two special pollutants. Researchers have started to focus on the development of detection methods [9], the improvement of existing treatment methods, and the development of new treatment methods, such as an advanced treatment process [10] and the use of metal oxides [11]. However, existing treatment methods used in cities are limited and new methods are imperfect. Therefore, improving existing treatment methods is the principal instrumentality.

Nano-materials, including carbon nanotubes (CNTs), have been developed rapidly [12]. Compared with activated carbon, CNTs contain a large number of unsaturated bonds and a small amount of functional groups, have larger specific surface area, lower weight, and better mechanical and electrochemical properties [13], and these parts could make CNTs serve as adsorbents, high-flux membranes, environmental sensors, and catalyst support [14]. Thus, CNTs can be employed as advanced treatment methods in wastewater treatment to remove non-degradable PPCPs [15].

In our previous studies, MWCNTs were proposed for effective removal of diclofenac in single-component solution [16]. The actual solutions are often twocomponent or multi-component. For this study we investigated the adsorption of diclofenac and triclosan in aqueous solutions on MWCNTs. We discussed the effects of different factors, including MWCNTs dosage, temperature, ion concentration, $\mathrm{pH}$, and initial concentration. The adsorption isotherms were established, kinetic and thermodynamic simulations conducted, and an IAS model was used to predict binary-solution adsorption. Furthermore, we discussed the adsorption mechanism.

\section{Materials and Methods}

\author{
Instruments and Reagents
}

The following instruments were used: a Thermo Orion 3-star benchtop pH meter (Thermo Fisher Scientific Inc.), a WS-900R shaking incubator (Wiggens, Germany), a UV2000 UV-visible spectrophotometer (Unico Instruments Co., Ltd., China), a 3K15 high-speed refrigerated centrifuge (Sigma, Germany), a precision electric oven (Thermo Fisher Scientific Inc.), and an LC-20AT highperformance liquid chromatography system (HPLC) (Shimadzu, Japan). For all experiments we utilized Milli-Q ultra-pure water (America Millipore).

The following reagents were used: diclofenac (Acros Organic, purity $>98 \%$, analytical grade), triclosan (Acros Organic, purity > 99\%, analytical grade), MWCNTs (Beijing Nachen Corporation, OD $=10-30$ $\mathrm{nm}$, length $=10-30 \mu \mathrm{m}$, specific surface area $>350 \mathrm{~m}^{2} \mathrm{~g}^{-1}$, purity $=85 \%$ ), $\mathrm{NaOH}$ (Acros Organic, purity $>98.5 \%$, analytical grade), $\mathrm{H}_{2} \mathrm{SO}_{4}$ (Acros Organic, purity $>98 \%$, analytical grade), and $\mathrm{HNO}_{3}$ (Acros Organic, purity = $68 \%$, analytical grade).

\section{Purification of MWCNTs}

The MWCNTs were purified respectively with $5 \mathrm{~mol} \mathrm{~L}^{-1}$ and $15 \mathrm{~mol} \mathrm{~L}^{-1} \mathrm{HNO}_{3}$. In the experiment, $5 \mathrm{~g}$ of MWCNTs were added to $250 \mathrm{~mL} \mathrm{HNO}_{3}$ solution in a three-neck round-bottom flask. The flask containing the mixture was heated for $8 \mathrm{~h}$ at $100^{\circ} \mathrm{C}$ and stirred during refluxing. Subsequently, the suspension was centrifuged at $8,000 \mathrm{rpm}$ for $3 \mathrm{~min}$. The precipitated materials were rinsed with deionized water to neutral and dried in the oven.

\section{Detection of Diclofenac and Triclosan}

In the pretreatment process we used the cellulose acetate membrane with a pore diameter of $0.22 \mu \mathrm{m}$ to filter the solution.

Diclofenac and triclosan concentrations were analyzed using HPLC.

Diclofenac: Shimadzu Shim-pack VP-ODS chromatographic column $(250 \mathrm{~mm} \times 4.6 \mathrm{~mm}, 5 \mu \mathrm{m})$; mobile phase A: methanol and mobile phase $\mathrm{B}$ : acetate buffer solution $(\mathrm{pH}=3.0)$; flow rate $=1.0 \mathrm{~mL} \mathrm{~min}$, $\mathrm{A}: \mathrm{B}=82: 18$; wavelength $=275 \mathrm{~nm}$; injection volume $=20 \mu \mathrm{L}$; and column temperature $=30^{\circ} \mathrm{C}$.

Triclosan: The same conditions, and wavelength $=281 \mathrm{~nm}$.

\section{Adsorption on MWCNTs}

The single-component solutions and binary aqueous solution were added to beaker flasks containing the appropriate purified MWCNTs dosage, and then shaken for $1 \mathrm{~h}$ under steady temperature. After adsorption, the 
suspension was filtered and the filtrate was stored for further testing. The experiment results were measured at least three times.

\section{Data Processing}

Removal efficiency was computed as follows:

$$
\eta_{t}=\frac{C_{0}-C_{t}}{C_{0}} \times 100 \%
$$

$\ldots$ where $\eta_{t}$ is the removal efficiency at time $t(\%), C_{0}$ is the initial solution concentration $\left(\mathrm{mg} \mathrm{L}^{-1}\right)$, and $C_{t}$ is the sample concentration at time $t\left(\mathrm{mg} \mathrm{L}^{-1}\right)$.

Adsorption capacity was computed as follows:

$$
q_{t}=\frac{V\left(C_{t}-C_{0}\right)}{m}
$$

...where $q_{t}$ is the adsorption capacity of MWCNTs at time $t\left(\mathrm{mg} \mathrm{g}^{-1}\right), V$ is the volume of the solution (L), $C_{t}$ is the solution concentration at time $t\left(\mathrm{mg} \mathrm{L}^{-1}\right)$, and $m$ is the MWCNT dosage (g).

The adsorption kinetics equations were as follows:

Pseudo zero-order: $\quad q_{t}=\frac{k_{0}}{t}+q_{e}$

Pseudo first-order: $\ln \left(q_{e}-q_{t}\right)=\ln q_{e}-k_{1} t$

Pseudo second-order: $\frac{t}{q_{t}}=\frac{1}{k_{2} q_{e}^{2}}+\frac{t}{q_{e}}$

Particle dispersion: $\quad q_{t}=k_{p} t^{0.5}$

... where $q_{t}$ is the adsorption capacity of MWCNTs at time $t\left(\mathrm{mg} \mathrm{g}^{-1}\right), t$ is time (min), and $q_{e}$ is the adsorption capacity at equilibrium ( $\left.\mathrm{mg} \mathrm{g}^{-1}\right)$. Other parameters such as $k_{0,} k_{1,} k_{2}$, and $k_{p}$ are all constants.

The adsorption isotherms and thermodynamic equations were as follows:
Freundlich isotherms: $\ln q_{e}=\ln k_{f}+\frac{\ln c_{e}}{n}$

Langmuir isotherms: $\frac{1}{q_{e}}=\frac{1}{x_{m}}+\frac{1}{x_{m} a_{l} c_{e}}$

$$
\Delta G^{0}=\Delta H^{0}-T \Delta S^{0}
$$

Arrhenius equation: $\quad K=A e^{-\frac{E_{a}}{R T}}$

Phase equilibrium parameter equation: $K=\frac{c_{s}}{c_{e}}$

IAS model based on Freundlich:

$$
C_{e, i}=\frac{q_{i}}{q_{t}}\left(\frac{\sum n_{j} q_{j}}{n_{i} K_{i}}\right)^{n_{i}}
$$

... where $c_{e}$ is the concentration of the sample at equilibrium $\left(\mathrm{mg} \mathrm{L}^{-1}\right)$. In Eq. 7, both $k_{f}$ and $1 / n$ are Freundlich constants, which are related to the adsorption capacity of the adsorbent and adsorption intensity, respectively. In Eq. 8, both $x_{m}$ and $a_{l}$ are Langmuir constants, which are related to adsorption energy. In Eq. $9, \Delta G^{0}, \Delta H^{0}$, and $\Delta S^{0}$ are normal Gibbs free energy $\left(\mathrm{kJ} \mathrm{mol}^{-1}\right)$, normal enthalpy change $\left(\mathrm{kJ} \mathrm{mol}^{-1}\right)$, and normal entropy change $\left(\mathrm{kJ} \mathrm{mol}^{-1}\right)$, respectively. In Eq. 10, $K$ is the rate constant, $A$ is the pre-exponential factor, and $E_{a}$ is the activation energy $\left(\mathrm{J} \mathrm{mol}^{-1}\right)$. In Eq. $11, K$ is the phase equilibrium parameter, $c_{s}$ is the volume of adsorbate adsorbed by a unit mass of adsorbent $\left(\mathrm{mmol} \mathrm{g}^{-1}\right)$, and $c_{e}$ is the concentration of adsorbate at equilibrium ( $\mathrm{mmol}$ $\left.\mathrm{mL}^{-1}\right)$. In Eq. 12, $q_{t}=\left(q_{t}+q_{2}\right), n_{i}$, and $K_{i}$ are parameters determined from Freundlich for the single-component solution adsorption.

\section{Results and Discussion}

\section{Characterization of MWCNTs}

Fig. S1a showed that the CNTs before purification were disorganized, the intertwining phenomenon was apparent, and lots of gaps were too narrow to be used
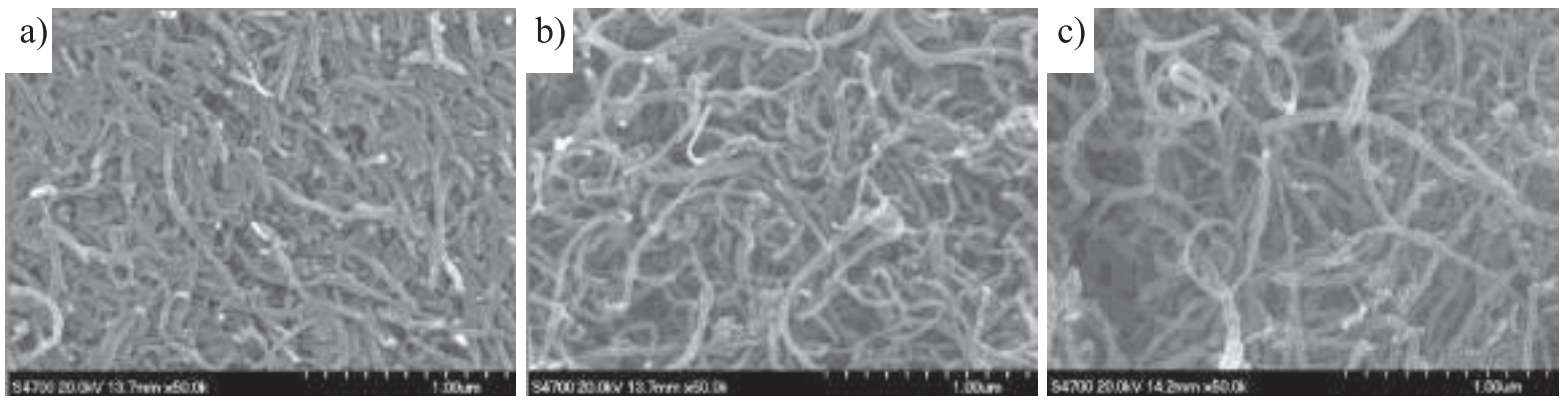

Fig. S1. SEM of MWCNTs a) before purification; b) $5 \mathrm{~mol} \cdot \mathrm{L}^{-1} \mathrm{HNO}_{3}$; c. $15 \mathrm{~mol} \cdot \mathrm{L}^{-1} \mathrm{HNO}_{3}$. 

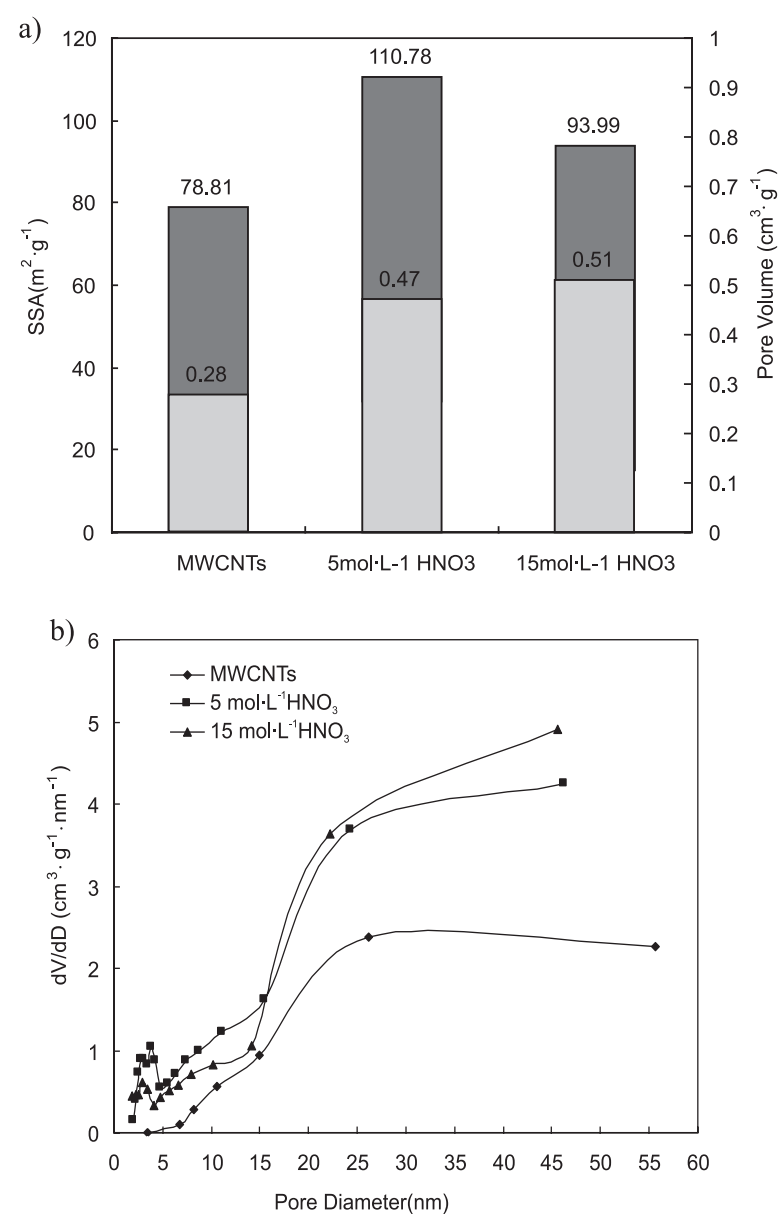

Fig. S2. SSA, Pore Volume, Pore Diameter of MWCNTs before and after purification.

by the adsorbates. Figs $\mathrm{S} 1 \mathrm{~b}$ and $\mathrm{S} 1 \mathrm{c}$ showed that the purification process changed the situation of curl, tangle, and aggregation, making the gaps between tubes bigger, and more adsorption sites on the tubular structure were released to be utilized by adsorbates. The values of SSA,

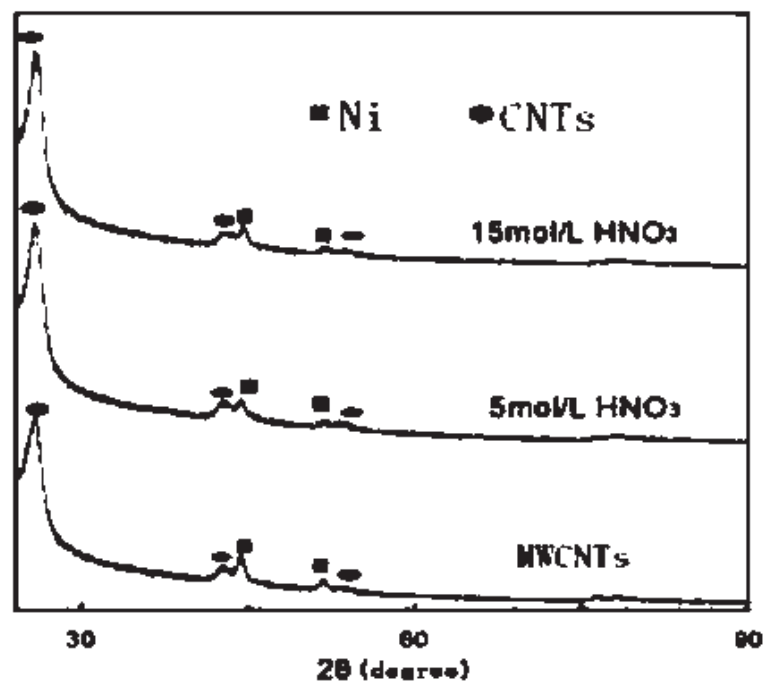

Fig. S3. XRD of MWCNTs before and after purification.

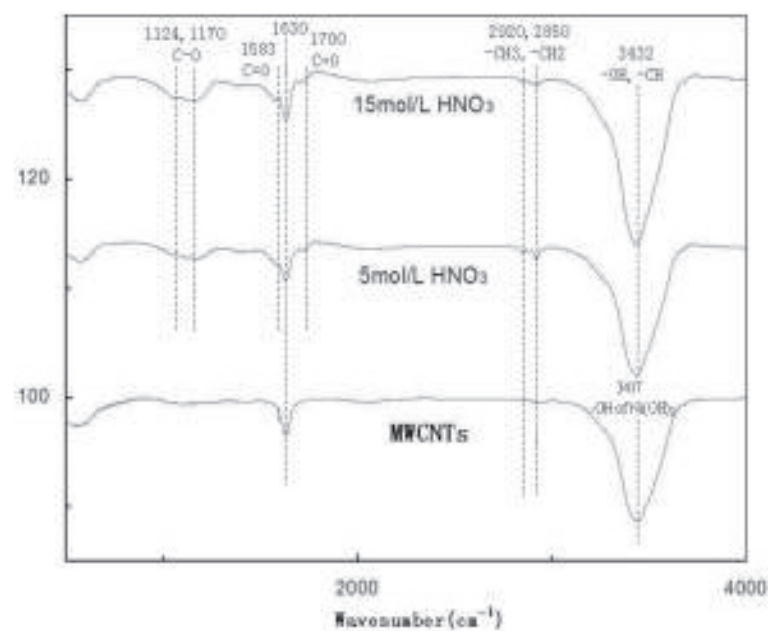

Fig. S4 FTIR spectra of MWCNTs before and after purification.

pore volume, and pore diameter were shown in Fig. S2, and the results verified that the $\mathrm{HNO}_{3}$ purification could increase MWCNTs specific surface area.

The characteristic diffraction peaks of MWCNTs were present in diffraction angles of $26.1^{\circ}, 43.2^{\circ}$, and $53.6^{\circ}$ (Fig. S3), proving that the graphite and six-membered carbocyclic ring were around the surface. The FTIR spectra (Fig. S4) presented the purified MWCNTs' absorption peaks of $1,630 \mathrm{~cm}^{-1}$, and the peaks of 2,920 $\mathrm{cm}^{-1}$, and $2,850 \mathrm{~cm}^{-1}$ were caused by stretching vibration of $-\mathrm{C}-\mathrm{H}\left(-\mathrm{CH}_{3},-\mathrm{CH}_{2}\right)$. Some functional groups were introduced as previous research had pointed out [17]. The peaks at $1,124 \mathrm{~cm}^{-1}$ and $1,170 \mathrm{~cm}^{-1}$ were generated by $-\mathrm{C}-\mathrm{O}$, the peaks at $1,583 \mathrm{~cm}^{-1}$ and $1,700 \mathrm{~cm}^{-1}$ were generated by $-\mathrm{C}=\mathrm{O}$ (e.g., $-\mathrm{COOH},-\mathrm{CH}-\mathrm{O})$, and the peaks at $1,583 \mathrm{~cm}^{-1}$ were aroused by $-\mathrm{O}-\mathrm{H}$ and $-\mathrm{C}-\mathrm{H}$. At last, we selected $5 \mathrm{~mol} \mathrm{~L}^{-1} \mathrm{HNO}_{3}$ as the final purification method because there was no obvious difference under the two $\mathrm{HNO}_{3}$ concentrations.

\section{Effect of MWCNTs Dosage}

Purified MWCNTs at different dosages were added into beaker flasks containing diclofenac or/and triclosan. The flasks were placed in a shaking incubator for $1 \mathrm{~h}$ at 298 K. Removal efficiency and adsorption capacity are shown in Fig. 1a.

Fig. 1a indicated that as MWCNTs dosage increased, the removal efficiency of both diclofenac and triclosan increased. The increase was mainly due to the availability of more adsorption sites provided by increasing MWCNTs dosage under the same initial concentration. For MWCNTs, a limited interwall space of $0.335 \mathrm{~nm}$ could hardly be used by organic matters such as triclosan, whose molecular width is $0.693 \mathrm{~nm}$, molecular height is $0.748 \mathrm{~nm}$, and molecular length is $1.419 \mathrm{~nm}$. Besides, the inner cavity was clogged by the metallic catalyst and agraphitic carbon before purification. After purification, functional groups formed in inner cavities [18] and the contact area became larger. Compared with inner cavities and interwall spaces, 
the external surface was available for organic matters, providing more adsorption sites. However, adsorption capacity declined. According to Eq. 2, when the increased extent of dosage was greater than the reduction extent of aqueous concentration, adsorption capacity might be reduced. Hence, the optimal dosage of MWCNTs was $0.1 \mathrm{~g}$, which met the requirements of high removal efficiency.

\section{Effect of Temperature}

MWCNTs dosage was selected as $0.1 \mathrm{~g}$. The other conditions remained the same. The results were shown in Fig. 1b.

Fig. 1b showed that removal efficiency and adsorption capacity decreased by about $15 \%$ and $5 \%$, respectively, with temperature increasing from $293 \mathrm{~K}$ to $313 \mathrm{~K}$. The adsorption was an exothermic process and the solubility of adsorbate had crucial effects. The solubility of adsorbate increased with the increase of the temperature, and chemical potential reduced with the increase of solubility. According to the energy conservation law, energy can be neither created nor destroyed, and it can convert into various forms (e.g., molecular energy) when temperature is increased. In addition, according to the kinetic theory, temperature is a sign of the average kinetic energy of molecules, and it is the collective performance of the large numbers of molecular thermal motions as well. In other words, random motion becomes more rambling, and organic matter molecules gain more power, making these molecules difficult to adsorb so that the removal efficiency and adsorption capacity were reduced.

Moreover, the removal efficiency and adsorption capacity of diclofenac are slightly higher than those of triclosan. At $293 \mathrm{~K}$, the removal efficiency and the adsorption capacity can meet the requirements of pollutant removal.

\section{Effect of Ion Concentration}

MWCNTs dosage and temperature were selected as optimal values. The other conditions remained the same. The ion concentration of the solution was adjusted with $\mathrm{Na}_{2} \mathrm{SO}_{4}$. The results are shown in Fig. 1c, where you can see that both removal efficiency and adsorption capacity meet an increase at first and a decrease afterwards with the increase of ion concentration, demonstrating that the ion could promote the adsorption of diclofenac and triclosan on purified MWCNTs in a certain concentration range. However, when ion concentration was high, the adsorption might occur between ions and purified MWCNTs. Thus, the optimal ion concentration was chosen as $15 \mathrm{~g} \mathrm{~L}^{-1}$.

\section{Effect of $\mathrm{pH}$ on Adsorption}

MWCNTs dosage, the temperature and the ion concentration were selected as the optimal values. The other conditions remained the same. The effect of $\mathrm{pH}$ on adsorption is shown in Fig. 1d.
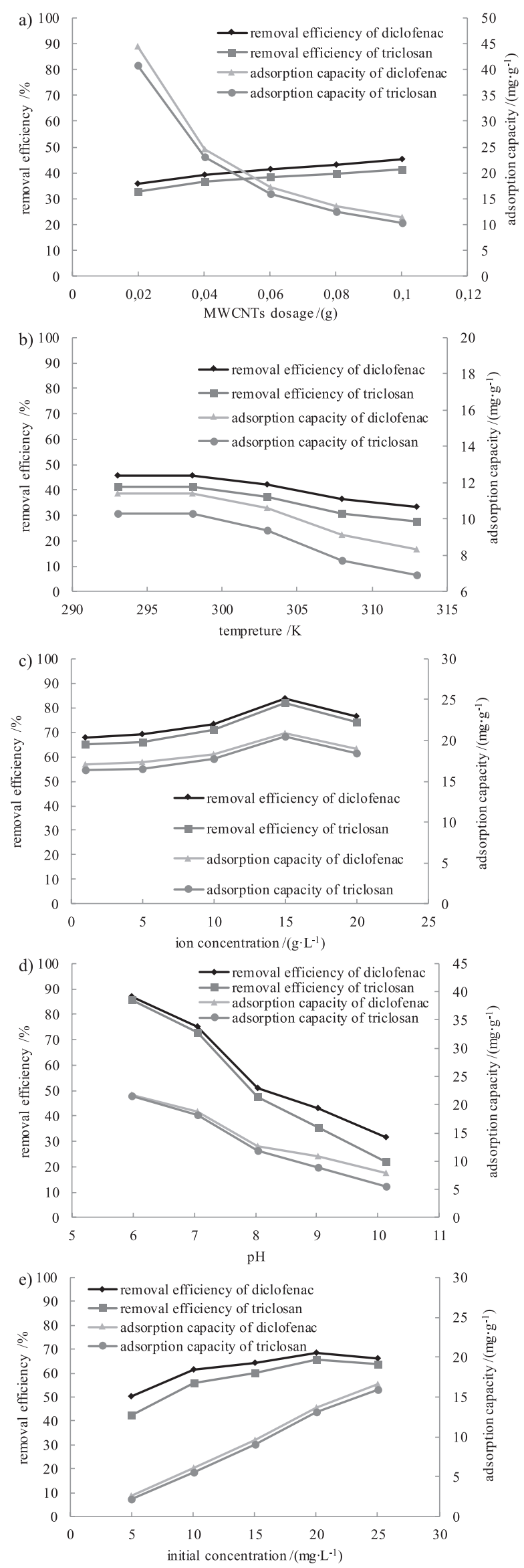

Fig. 1. Effect of different factors on adsorption a) MWCNTs dosage; b) temperature; c) ion concentration; d) $\mathrm{pH}$; e) initial concentration. 
As shown in Fig. 1d, the removal efficiency and adsorption capacity decrease rapidly with the increase of $\mathrm{pH}$. The decrease of adsorption capacity can be explained by electrostatic interaction [19]. Both diclofenac and triclosan have $\mathrm{Cl}$ atoms in structure, and diclofenac and triclosan were dissociated into the anions and the MWCNTs got charged negatively as $\mathrm{pH}$ increased. Thus, the electrostatic repulsion between the adsorbates and the negatively charged MWCNTs weakened the adsorption capacity. In addition to electrostatic interaction, there are other reasons which can cause the results, such as watersolubility of diclofenac and triclosan. The water-solubility of diclofenac and triclosan increased with the increase of $\mathrm{pH}$, as a consequence of which both removal efficiency and adsorption capacity reduced. Considering the $\mathrm{pH}$ varied from 6.0 to 9.0 in the actual wastewater discharge, we chose 7.0 as the optimal $\mathrm{pH}$.

\section{Effect of Initial Concentration}

The other conditions were selected for optimal value. The effect of initial concentration on adsorption is shown in Fig. 1e, where both removal efficiency and adsorption capacity increase with the increase of initial concentration. The first reason for this was that not all of the adsorption sites can be used by diclofenac and triclosan for the low initial concentration. The second reason was that the initial concentration can provide a strong driving force to overcome mass transfer resistance between the adsorbent and adsorbate. Hence, at an initial concentration of about $50 \mathrm{mg} \mathrm{L}^{-1}$, the adsorption sites can be utilized adequately and mass transfer resistance can be overcome to a large extent, leading to maximum removal efficiency and adsorption capacity.

\section{Kinetics}

The adsorption process was simulated using four kinds of kinetic formulas under optimal conditions. The adsorption of diclofenac and triclosan on MWCNTs could be fitted well with the pseudo-second-order kinetics equation, and the linear correlation coefficient $\mathrm{R}^{2}$ at 293 K equaled 0.9997 and 0.9998 . Under the same conditions, the adsorption processes still belonged to the pseudosecond-order kinetics equation at $303 \mathrm{~K}$ and $313 \mathrm{~K}$. Furthermore, according to Eq. 10, the activation energy $E_{a}$ of triclosan equaled $0.32 \mathrm{~kJ} \mathrm{~mol}^{-1}$ and that of diclofenac was $-3.74 \mathrm{~kJ} \mathrm{~mol}^{-1}$. The value suggested that the process was not as easy as supposed. Adsorption mechanisms such as electron transfer [20] must be considered.

The value of $E a$ for diclofenac adsorption was negative, suggesting that the adsorption of diclofenac on MWCNTs was a complex process. According to modern molecular collision theory and Tolman's interpretation [21], the threshold energy of the diclofenac adsorption may be equal to 0 and adsorption efficiency may drop with increasing temperature. All the processes were exothermic, which was inconsistent with the triclosan adsorption in this study.

\section{Thermodynamics}

Adsorption isotherms at different temperature levels are shown in Fig. 2. The process was simulated using two adsorption isotherms (see Table 1). The results show that the process could be fitted well with the Langmuir (monolayer reversible adsorption process) and Freundlich isotherms. Based on the designed procedure provided by Chen et al. [22], thermodynamic parameter values could be obtained, as shown in Table 2: $\Delta H<0, \Delta G<0$, and $\Delta S$ $<0$, which suggested that adsorption was a spontaneous and exothermic process.

The surface of MWCNTs is made up of polygene, which is rich in $\pi$-electron and resulting in the $\pi-\pi$ conjugate with $\pi$-electron in the benzene ring. The structures of the two typical PPCPs have benzene rings, so there is a strong adsorption force between the sorbent and the adsorbate. The process can emit more heat. Thus, it is estimated as an exothermic process.

According to the theory of adsorption exchange, the solute molecule could lose part of the degree of freedom when the solute molecule moves to the solidliquid interface in the adsorption process. The MWCNTs adsorption is an entropy reduction process. When the
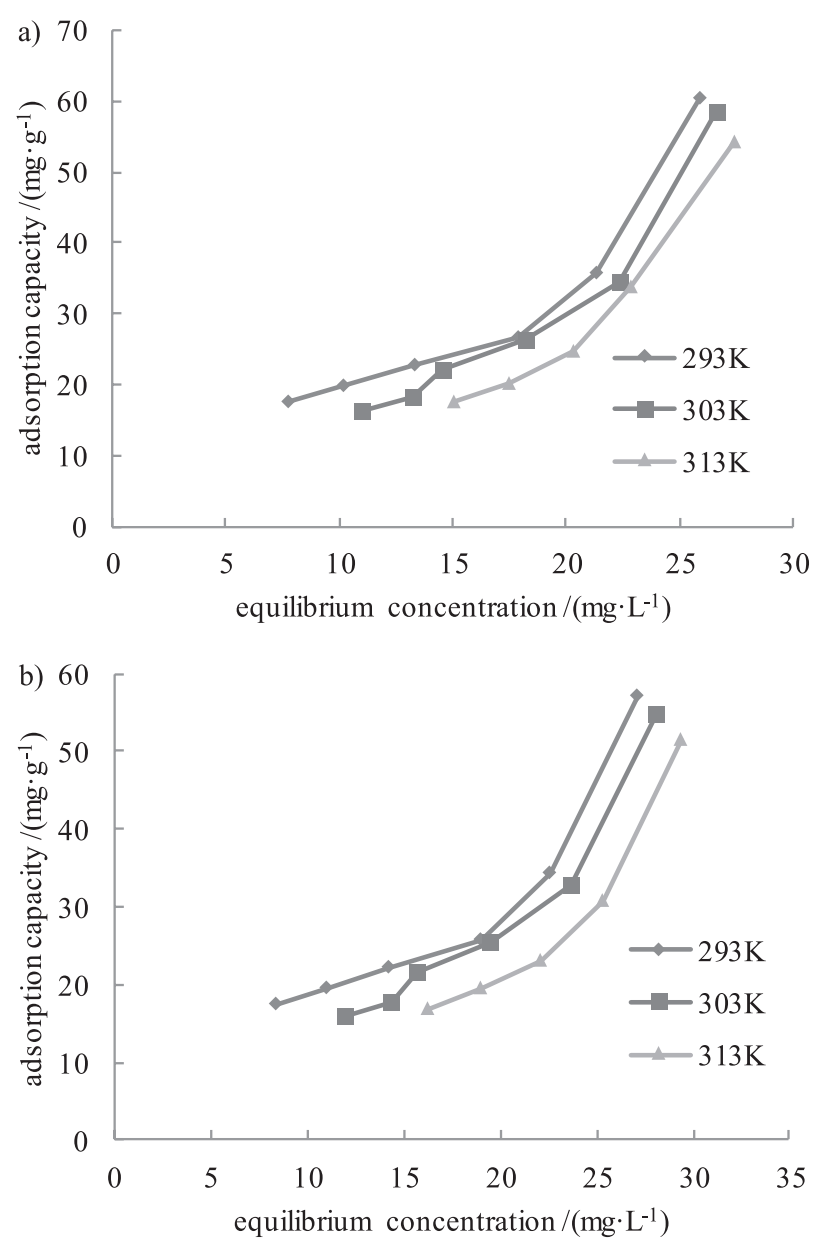

Fig. 2. Adsorption isothermal equilibrium at different temperatures a) diclofenac; b) triclosan. 
Table 1. Adsorption thermodynamic simulation of diclofenac and triclosan.

\begin{tabular}{|c|c|c|c|c|c|c|c|}
\hline \multirow{2}{*}{ Compound } & \multirow{2}{*}{$\mathrm{T} / \mathrm{K}$} & \multicolumn{3}{|c|}{ Freundlich } & \multicolumn{3}{c|}{ Langmuir } \\
\cline { 2 - 8 } & & $k_{f}$ & $n$ & $\mathrm{R}^{2}$ & $a_{l}$ & $x_{m}$ & $\mathrm{R}^{2}$ \\
\hline \multirow{3}{*}{ Diclofenac } & 293 & 2.4368 & 1.1047 & 0.9708 & 0.0237 & 106.38 & 0.9522 \\
\cline { 2 - 8 } & 303 & 0.5686 & 0.7340 & 0.9676 & -0.0112 & -111.11 & 0.9399 \\
\cline { 2 - 8 } & 313 & 0.0821 & 0.5156 & 0.9724 & -0.0211 & -35.97 & 0.9486 \\
\hline \multirow{3}{*}{ Triclosan } & 293 & 2.1873 & 1.1001 & 0.9681 & 0.0212 & 106.38 & 0.9494 \\
\cline { 2 - 8 } & 303 & 0.4769 & 0.7275 & 0.9669 & -0.0113 & -100.12 & 0.9409 \\
\cline { 2 - 8 } & 313 & 0.0966 & 0.5522 & 0.9536 & -0.0171 & -40.82 & 0.9199 \\
\hline
\end{tabular}

Table 2. Thermodynamic parameters of the adsorption process.

\begin{tabular}{|c|c|c|c|c|}
\hline \multirow{3}{*}{ Compound } & $\mathrm{T} / \mathrm{K}$ & $\Delta \mathrm{G} /\left(\mathrm{kJ} \cdot \mathrm{mol}^{-1}\right)$ & $\Delta \mathrm{H} /\left(\mathrm{kJ} \cdot \mathrm{mol}^{-1}\right)$ & $\Delta \mathrm{S} /\left(\mathrm{J} \cdot \mathrm{mol}^{-1} \cdot \mathrm{K}^{-1}\right)$ \\
\hline \multirow{4}{*}{ Diclofenac } & 293 & -18.12 & -25.87 & -26.45 \\
\cline { 2 - 5 } & 303 & -17.82 & -25.87 & -26.57 \\
\cline { 2 - 5 } & 313 & -17.59 & -25.87 & -26.45 \\
\hline \multirow{4}{*}{ Triclosan } & 293 & -17.86 & -27.01 & -31.23 \\
\cline { 2 - 5 } & 303 & -17.52 & -27.01 & -31.32 \\
\cline { 2 - 5 } & 313 & -17.23 & -27.01 & -31.25 \\
\hline
\end{tabular}

adsorption process is carried out, large amounts of water molecules are desorbed from the MWCNTs surface, indicating that it is an entropy increase process. Even though the two processes exist simultaneously, the final result shows that it is inclined to entropy reduction.

\section{Binary Solution Adsorption Prediction}

The thermodynamic results showed that the adsorption could be better simulated with Freundlich isotherms, so the isotherm parameters from the single-solute adsorption Freundlich model were employed to evaluate the binary solution adsorption. As shown in Fig. 3, the experimental results are in accordance with the predicted values. This indicated that the IAS model was capable of representing MWCNTs adsorption in binary solutions and that the parameters obtained from single-solution adsorption could be applied. The IAS model could predict the interaction between compounds and MWCNTs, including any competitive effects [23].

\section{Adsorption Mechanism}

Adsorption process involves a variety of forces, the most important of which is the Van Der Waals force, especially for hydrophobic adsorbents. In addition, the adsorption process is also related to the relationships between adsorbents and adsorbates, such as hydrophobic effect, $\pi-\pi$ bond, hydrogen bond, covalent bond, and electrostatic interactions [24]. The adsorption mechanism is analyzed in this study, as shown in Fig. 4. Purified MWCNTs, diclofenac, and triclosan all have special functional groups $(-\mathrm{COOH},-\mathrm{OH})$ that can be hydrogen bond contributors, so hydrogen bond and van der waals force are considered the main forces.

Besides the two forces mentioned above, there are $\pi-\pi$ bond, hydrogen bond, covalent bond, hydrophobic effects, and electrostatic interactions. The surface of MWCNTs is made up of polyene, which is rich in $\pi$-electron and results in the $\pi-\pi$ conjugate with $\pi$-electron in the benzene ring. The structures of the two typical PPCPs have benzene rings. Moreover, triclosan has $-\mathrm{OH}$, which can reduce

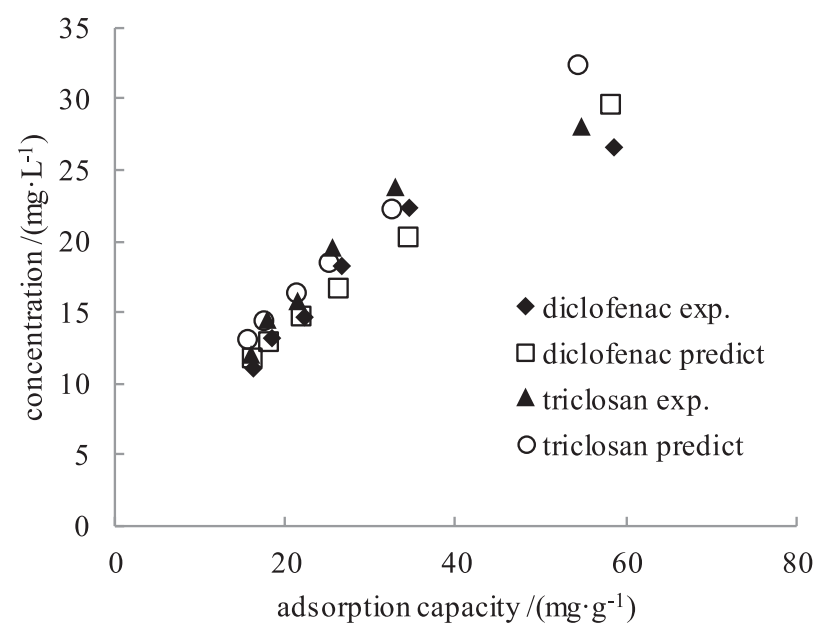

Fig. 3. IAS model simulation of binary solution. 


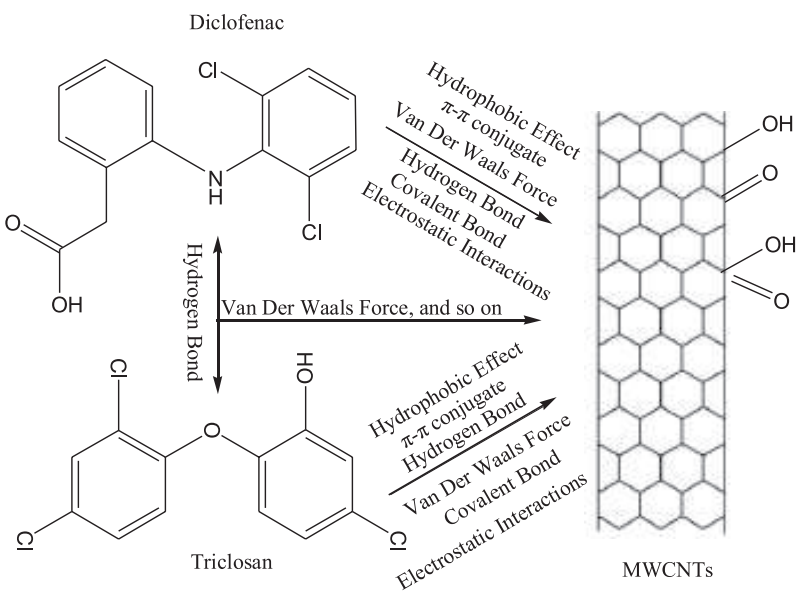

Fig. 4. Analysis of adsorption mechanism.

electron cloud density. In the meantime, they all have carboxyl and hydroxyl, so the covalent bond can be forged between them.

According to Eq. 11, the values of the phase equilibrium parameters of diclofenac and triclosan are 1,329 and 1,203, respectively, which proves that the adsorption capacity of diclofenac is larger than that of triclosan. An analysis of molecular models shows that diclofenac has a better planar structure compared with triclosan, and researchers found that polycyclic aromatic hydrocarbons with a planar structure could integrate well with CNTs through a conjugated system [25].

\section{Conclusions}

The purified MWCNTs were used to remove diclofenac and triclosan. The research showed that MWCNTs had an effect not only on single-solute adsorption, but also on bi-solute adsorption. Kinetic and thermodynamic study laid the theoretical foundation for adsorption. Besides, the adsorption mechanism was revealed and the main conclusions are listed as follows:

1) The purification of MWCNTs promoted the adsorption effect and many analysis methods, including SEM, SSA, XRD, TGA, and FTIR, characterized by the change of purified MWCNTs.

2) When MWCNTs dosage was $0.1 \mathrm{~g}$, temperature was $298 \mathrm{~K}$, ion concentration was $15 \mathrm{~g} \times \mathrm{L}^{-1}, \mathrm{pH}$ was 7.0 , initial concentration was $50 \mathrm{mg} \mathrm{L}^{-1}$, and equilibrium adsorption capacity was $19.9 \mathrm{mg} \mathrm{g}^{-1}$ for diclofenac and $19.7 \mathrm{mg} \mathrm{g}^{-1}$ for triclosan after $60 \mathrm{~min}$.

3) The adsorption process conformed to the pseudosecond-order kinetics equation. The thermodynamic simulation showed that the process was fitted with Freundlich and Langmuir isotherms, and the thermodynamic parameters estimated that the adsorption was spontaneous and exothermic.

4) The IAS model successfully predicted the binary solution adsorption.

\section{Acknowledgments}

This research was financially supported by the National Natural Science Foundation of China with grant Nos. 51178022 and 51278022.

\section{References}

1. FOOLAD M., ONG S. L., HU J. Transport of sewage molecular markers through saturated soil column and effect of easily biodegradable primary substrate on their removal. Chemosphere. 138, 553, 2015.

2. NAM S.W., JUNG C., LI H., YU M., FLORA J.R.V., BOATENG L. K., HER N., ZOH K. D., YOON Y. Adsorption characteristics of diclofenac and sulfamethoxazole to graphene oxide in aqueous solution. Chemosphere. 136, 20, 2015.

3. LIN Y. L., LI B.K. Removal of pharmaceuticals and personal care products by Eichhornia crassipe and Pistia stratiotes. J. Taiwan Inst. Chem. E. 58, 318, 2016.

4. ZHANG H., HU X. Adsorption of Cephalosporins from Aqueous Solutions by Multi-walled Carbon Nanotubes. Pol. J. Environ. Stud. 24 (5), 2285, 2015.

5. ATTIA T.M.S., HU X.L., QIANG Y.D. Synthesized magnetic nanoparticles coated zeolite for the adsorption of pharmaceutical compounds from aqueous solution using batch and column studies. Chemosphere. 93, 2076, 2013.

6. COELHO A.D., SANS C., AGÜERA A., GÓMEZ M.J., ESPLUGAS S., DEZOTTI M. Effects of ozone pre-treatment on diclofenac: intermediates, biodegradability and toxicity assessment. Sci. Total. Environ. 407 (11), 3572, 2009.

7. CHEN W., XU J., LU S., JIAO W., WU L., CHANG A.C. Fates and transport of PPCPs in soil receiving reclaimed water irrigation. Chemosphere. 93, 2621, 2013.

8. XU J., WU L., CHANG A.C. Degradation and adsorption of selected pharmaceuticals and personal care products (PPCPs) in agricultural soils. Chemosphere. 77, 1299, 2009.

9. LU H., MA H., TAO G. Spectrophotometric determination of triclosan in personal care products. Spectrochim. Acta A. 73 (5), 854, 2009.

10. NAZARI G., ABOLGHASEMI H., ESMAIELI M. Batch adsorption of cephalexin antibiotic from aqueous solution by walnut shell-based activated carbon. J. Taiwan Inst. Chem. E. 58, 357, 2016.

11. FORREZ L., CARBALLA M., VERBEKEN K., VANHAECKE L., SCHLÜSENER M., TERNES T., BOON N., VERSTRAETE W. Diclofenac oxidation by biogenic manganese oxides. Environ. Sci. Technol. 44 (9), 3449, 2010.

12. ATLAGIĆ G. S., YANG C. M., HATTORI Y., TAKAHASHI K., KANOH H., KANEKO K. Adsorption of polyaromatic hydrocarbons on single wall carbon nanotubes of different functionalities and diameters. J. Colloid Interface Sci. 314 (1), 18, 2007.

13. MAUTER M.S., ELIMELECH M. Environmental applications of carbon-based nanomaterials. Environ. Sci. Technol. 42 (16), 5843, 2008.

14. YANG K., XING B. Adsorption of organic compounds by carbon nanomaterials in aqueous phase: polanyi theory and its application. Chem. Rev. 110 (10), 5989, 2010.

15. WANG Y., BI C. Y. A novel nitrite biosensor based on direct electron transfer of hemoglobin immobilized on a graphene oxide/Au nanoparticles/multiwalled carbon nanotubes nanocomposite film. RSC Adv. 4 (60), 31573, 2014. 
16. HU X., CHENG Z. Removal of diclofenac from aqueous solution with multi-walled carbon nanotubes modified by nitric acid. Chin. J. Chem. Eng. 23 (9), 1551, 2015.

17. WANG F., YAO J., CHEN H., YI Z., XING B. Sorption of humic acid to functionalize multi-walled carbon nanotubes. Environ. Pollut. 180, 1, 2013

18. VILIAN A.T.E., CHEN S.M. Direct electrochemistry and electrocatalysis of glucose oxidase based poly(L-arginine)multiwalled carbon nanotubes. RSC Adv. 4 (92), 50771, 2014.

19. YANG K., XING B. Adsorption of fulvic acid by carbon nanotubes from water. Environ. Pollut. 157 (4), 1095, 2009.

20. BAGHAYERI M., VEISI H., VEISI H, MALEKI B., KARIMI-MALEH H., BEITOLLAHI H. Multi-walled carbon nanotubes decorated with palladium nanoparticles as a novel platform for electrocatalytic sensing applications. RSC Adv. 4 (91), $49595,2014$.

21. KO D.C.K., PORTER J.F., MCKAY G. Application of the concentration-dependent surface diffusion model on the multicomponent fixed-bed adsorption systems. Chem. Eng. Sci. 60 (20), 5472, 2005.

22. CHEN R.J., ZHANG Y., WANG D., DAI H. Noncovalent sidewall functionalization of single-walled carbon nanotubes for protein immobilization. J. Am. Chem. Soc. 123 (16), 3838, 2001.

23. YEONG Y.F., ABDULLAH A.Z., AHMAD A.L., BHATIA $\mathrm{S}$. Separation of $\mathrm{p}$-xylene from binary xylene mixture over silicalite-1 membrane: experimental and modeling studies. Chem. Eng. Sci. 66 (5), 897, 2011.

24. DENG S., ZHANG Q., NIE Y., WEI H., WANG B., HUANG J., YU G., XING B. Sorption mechanisms of perfluorinated compounds on carbon nanotubes. Environ. Pollut. 168 (5), 138, 2012.

25. HU X., MU L., ZHOU Q., WEN J., PAWLISZYN J. ssDNA aptamer-based column for simultaneous removal of nanogram per liter level of illicit and analgesic pharmaceuticals in drinking water. Environ. Sci. Technol. 45 (11), 4890, 2011. 
